\title{
Insilico Anti-COVID Study of New-fangled High Polar Zr(IV) Complexes Functionalized with Resacetophenone and NMP Ligands
}

\author{
M. Santhiya ${ }^{1} \&$ T. Lurthu Pushparaj ${ }^{2 *}$ \\ ${ }^{1}$ Department of Chemistry, UG, T.D.M.N.S College, Tamil Nadu, India. \\ ${ }^{2 *}$ Assistant Professor, Department of Chemistry, PG, T.D.M.N.S College, Tamil Nadu, India. Email: chemlurthu2006@ gmail.com \\ DOI: http://doi.org/10.38177/AJBSR.2021.3205
} Crossref

Copyright: (02021 M.Santhiya \& T.Lurthu Pushparaj. This is an open access article distributed under the terms of the Creative Commons Attribution License, which permits unrestricted use, distribution, and reproduction in any medium, provided the original author and source are credited.

\section{ABSTRACT}

A significant issue restricting their commercialization is the short dependability of utilitarian biomolecules. These days, enduring immunizations, antiviral specialists, and anti-infection agents without zero results are intriguing examination subjects. In continuation of our pandemic exploration interest focused on the advancement of the keen antiviral specialist for COVID-19 utilizing heterocyclic metal builds. We describe herein synthesis and structural characterization of two new $\mathrm{Zr}(I V)$ complexes containing ligands like resacetophenone (T-R-Zr) (I) and N-methyl-2-pyrrolidone (T-NMP-Zr) (II). The absorption character in a neat solvent, in presence of $4.5 \%$ BSA, and the biological interaction of COVID-19 virus through molecular docking have been summarized taking the scope into coordination chemistry directly or indirectly. The two complexes in $4.5 \%$ of BSA display both blue and red shift in peaks corresponds to LCT and MLCT transitions. The molecular docking study of the complex with the crystal structure of SARS-Coronavirus-2 (PDB: 6LU7) shows strong polar interaction with various amino acids present in the spike protein. The complex

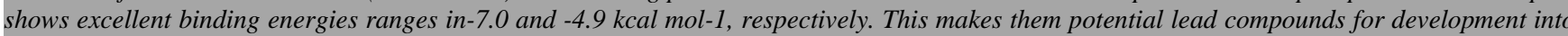
candidates against the SARS-Coronavirus-2. The absorption spectral behavior insolvent and in $4.5 \%$ BSA has been found to show the importance of our complex in biological application especially in COVID-19 treatment studies. Furthermore, we investigated the basic energies like potential and steric energy of the complex through Gaussian energy calculations.

Keywords: Resacetophenone, Pyrolidone, Zr(IV) complex, BSA Binding, SARS-COV-2 Docking, M-Protease.

\section{Introduction}

The Schiff bases play an important role in chemistry. During the last 20 years extensive awareness on the metal complexes of Schiff bases [1,2] containing nitrogen and other donors. The transition metal complexes of Schiff bases are very fascinating because of the presence of both hard nitrogen and oxygen donor atoms in the backbones of these ligands, some of these complexes have been exhibit remarkable physicochemical properties and potentially useful biological activities.[3,4] Amine and hydroxide bases are known for their wide range of biological activities, including antifungal, anticancer, antibacterial, antimalarial, antiproliferative, anti-inflammatory, antiviral, and antipyretic effects. Resacetophenone is a bi-dentate ligand. 2',4'-Dihydroxyacetophenone, also known as 4-acetylresorcinol, belongs to the class of organic compounds known as alkyl-phenyl ketones.

These are aromatic compounds containing a ketone substituted by one alkyl group and a phenyl group. 2',4'-Dihydroxyacetophenone is an extremely weak basic (essentially neutral) compound (based on its pKa). Three Schiff bases of Mannich bases of resacetophenone have been reported by using three variable electronegative atoms $(\mathrm{X}=\mathrm{O} / \mathrm{S} / \mathrm{NH})$ of urea/thiourea/guanidine and tested for antimicrobial activity and antioxidant screening by DPPH. Resacetophenone a well-known complexing agent is able to coordinate with a wide number of metal ions. It is also well known as a pharmaceutical agent [5-8].

A number of heterocyclic compounds show pharmaceutical as well as biological activity. N-Methyl-2-pyrrolidone (NMP) is an organic compound belongs to the class of dipolar aprotic solvents such as dimethylformamide and dimethylsulfoxide. In the pharmaceutical industry, $\mathrm{N}$-methyl-2-pyrrolidone is used in the formulation of drugs by 
both oral and transdermal delivery routes [9]. Studies in humans show comparable results. NMP is rapidly biotransformed by hydroxylation to 5-hydroxy-N-methyl-2-pyrrolidone, which is further oxidized to $\mathrm{N}$-methylsuccinimide; this intermediate is further hydroxylated to 2-hydroxy-N-methylsuccinimide [10].

Zirconia $\left(\mathrm{ZrO}_{2}\right)$ prosthetics were developed as an alternative to titanium, steel, and aluminum and were shown to be both more resilient and with better biocompatibility. Approximately 300,000 patients over the past four decades with zirconia prosthetics have shown no negative responses. It is more compatible with the human body and has twice the flexural strength and four times the compression resistance of steel.

It also has greater resistance to acid bases found in many foods. Bovine serum albumin is a serum albumin protein isolated from cows. Rockland produces BSA in various formats for use in immunology, biochemistry, and biotechnology. BSA is also used as a nutrient in cell and microbial culture. In molecular biology, BSA is used to stabilize some restriction enzymes during the digestion of DNA. BSA is considered to be a universal blocking reagent in many applications-this is because BSA does not affect the functions of other proteins (enzymes) that do not need it for stabilization.

BSA is used because of its stability to increase signal in assays, its lack of effect in many biochemical reactions, and its low cost since large quantities of it can be readily purified from bovine blood, a byproduct of the cattle industry. Severe acute respiratory syndrome coronavirus-2 (SARS-CoV-2) infection in humans can cause pneumonia, acute respiratory distress syndrome, acute lung injury, cytokine storm syndrome and death [11,12].

Although SARS-CoV-2 infection primarily causes respiratory disease; some patients develop symptoms of neurological disease, such as headache, loss of taste and smell, ataxia, meningitis, cognitive dysfunction, memory loss, seizures and impaired consciousness [13-20]. COVID-19 has been shown to bind to ACE2 via the S protein on its surface. During infection, the $\mathrm{S}$ protein is cleaved into subunits, $\mathrm{S} 1$ and $\mathrm{S} 2$.

These structures have previously not been identified and could aid in producing antivirals or a vaccine that can block coronavirus infection by targeting ACE2. Several researchers have been racing to understand the peculiar nature of the virus and the pathogenesis of the disease to uncover possible drug targets. So for a number of transition metal complexes by using a variety of $\mathrm{N}$ - and $\mathrm{O}$-donor ligands and have studied their different biological activities such as antimicrobial, anticancer, antifungal.

Thus, monitoring molecular docking levels in antiviral activity, antibacterial, anticancer, and antifungal activity is a promising target therapy for evaluating response to conventional COVID-19 treatments [21-25]. The complexes of resacetophenone and $\mathrm{N}$-methyl 2-pyrolidone with $\mathrm{Zr}$ have been found to show antibacterial and anticancer activity, respectively. Due to bacterial and viral resistance to the currently available antibiotics, there has been growing interest in developing new drugs with better activity. Moreover, it is known that ligands having N-and O- atoms show pronounced biological activity due to enhancement in coordination behavior.

In this article we prepared two $\mathrm{Zr}(\mathrm{IV})$ metal complex with resacetophenone and $\mathrm{N}$-methyl 2-pyrolidone and the complexes are subjected to anti-covid study by analyzing through BSA protein binding efficiency using Uv-Vis spectroscopy and insilico Molecular docking study. 
Asian Journal of Basic Science \& Research Volume 3, Issue 2, Pages 40-50, April-June 2021

\section{Experiment Methods}

2.1. Materials and methods: All the chemicals and solvents were purchased in AR grade from merk, India and used as such. CHN Microanalyses: CHN microanalyses were carried out using a Perkin-Elmer 2400 Series II CHNS/O Elemental Analyzer, interfaced with a Perkin-Elmer AD 6 Autobalance. Helium was used as the carrier gas. Caution! All hygroscopic compounds were dried in desiccator over silica gel for $24 \mathrm{~h}$ prior to the analysis. Uv-Visible Absorption Spectrum: The electronic spectra were recorded in the 200-900 nm regions on Deep vision UV/VIS spectrophotometer using cuvette with a $1 \mathrm{~cm}$ path length. The concentration of ligand and metal complexes was kept at $1.00 \times 10^{-5} \mathrm{~mol} \mathrm{~L}^{-1}$, at $310 \mathrm{~K}$. Basic crystallographic energy calculations were performed by using advanced Gaussian algorithm.

2.2. BSA binding studies: The electronic absorption properties of the edifices within BSA protein were studied by treating the complexes with $4.5 \% \mathrm{BSA}$ in water till equilibrium is achieved and by estimating the assimilation for the diverse time periods minutes to 2 days. All ingestion estimations were done in a Uv-Visible spectrometer and the qualities are recorded at $310 \mathrm{~K}$.

2.3. Molecular docking study: Molecular docking concentrates on the edifices that have been performed utilizing HEX 5.0 programming and Q-site locater, which is an intuitive molecular illustrations program for the connection, docking estimations, and to distinguish conceivable restricting destinations of the biomolecules [26]. The directions of the metal complex have been taken from the enhanced construction as a .mol document and have been changed over to PDB design utilizing PYMOL programming. The crystal structure of Coronavirus (PDB: 6LU7) has been recovered from the protein information bank (http://www.rcsb.org/.pdb). Perception of the docked frameworks has been performed utilizing PYMOL Tool. Default boundaries were utilized for the docking computations with connection type shape and FFT mode at 3D level, lattice measurement of 6 with receptor range 180, ligand range 180 with curve range 360 , and distance range 40.

2.4. Synthesis of Resacetophenone: The zinc chloride $(16.5 \mathrm{~g})$ is fused in a porcelain basin until it shows a tendency of fume, then poured into a clean mortar, powdered quickly, and kept in desiccators, ready for use [27]. Glacial acetic acid $(16 \mathrm{~mL})$ is taken in a beaker and the zinc chloride dissolved in it by heating. Resorcinol $(11 \mathrm{~g})$ is added slowly with a constant string. The mixture is heated until boiling $\left(142^{\circ} \mathrm{C}\right)$ and allows cooling (Scheme-1). The syrupy liquid is then treated with a mixture of concentrated hydrochloric acid and water 1:1 a crystalline mass is obtained slowly. The crystals are filtered off, washed with water, and dried. A small portion of the sample is recrystallized from boiling water pale orange-yellow plates are obtained. Yield $5.01 \mathrm{~g} \mathrm{(94.4 \% ),} \mathrm{mp} 197 \mathrm{oC}$. Anal. calc. \% for $\mathrm{C}_{8} \mathrm{H}_{8} \mathrm{O}_{3}(\mathrm{Mr}=152)$ : C, 73.55; $\mathrm{H}, 13.79 ; \mathrm{O}, 12.04$. Found: $\mathrm{C}, 72.28 ; \mathrm{H}, 13.63 ; \mathrm{O}, 12.16$.

2.5. Synthesis of Tetra-Resacetophenone-Zirconium (IV) complex (T-R-Zr): About $1.24 \mathrm{~g}$ (8 mmol) Resacero phenone and $0.64 \mathrm{~g}(2 \mathrm{mmol}) \mathrm{ZrOCl}_{2} .8 \mathrm{H}_{2} \mathrm{O}$ in $50 \mathrm{~mL}$ of a solvent of $\mathrm{H}_{2} \mathrm{O}$, were heated at $120{ }^{\circ} \mathrm{C}$ under stirring for 24 hours. After the reaction was completed, the mixture was cooled to room temperature (Scheme-1). The obtained yellow color clear solution was evaporated to dryness. The yellow colour Zirconium complex obtained has been recrystallized from water, yield $4.12 \mathrm{~g}(98 \%)$, mp (dec.) $197{ }^{\circ} \mathrm{C}$. Anal. calc. \% for $\mathrm{C}_{32} \mathrm{H}_{28} \mathrm{O}_{12} \mathrm{Zr}(\mathrm{Mr}=695.79)$ : C, $55.24 \%$; $4.06 \%$; O, $27.59 \%$;r, $13.11 \%$. Found: C, $55.18 \%$; H, $3.51 \%$; O, $27.33 \%$;r, $12.99 \%$ 

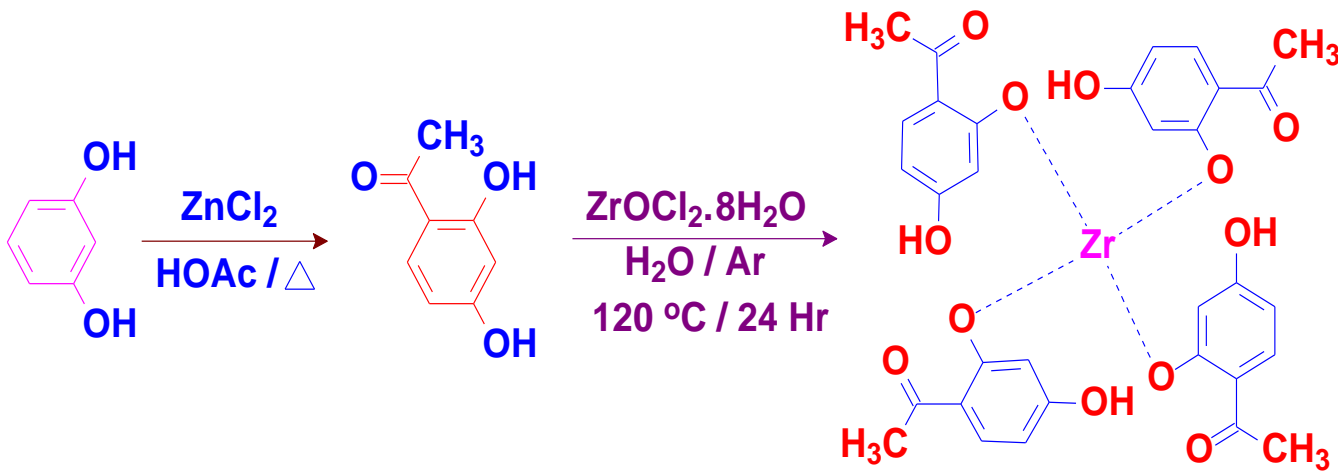

\section{T-R-Zr (Complex - I)}

Scheme 1. Synthesis of Resorcinol and its $\operatorname{Zr}(\mathrm{IV})$ Complex

2.6. Synthesis of tetra-N-Methyl-2-pyrolidone-Zr(IV) complex (T-NMP-Zr): About $1.5 \mathrm{~mL}$ (8 mmol) N-Methyl2-Pyrolidone and $1.28 \mathrm{~g} \mathrm{(2} \mathrm{mmol)} \mathrm{ZrOCl}_{2} .8 \mathrm{H}_{2} \mathrm{O}$ in $50 \mathrm{~mL}$ of a solvent of $\mathrm{H}_{2} \mathrm{O}$, were heated at $120{ }^{\circ} \mathrm{C}$ under stirring for 24 hours. After the reaction was completed, the mixture was cooled to room temperature (Scheme-2). The obtained clear solution was evaporated to dryness. The colourless Zirconium complex obtained has been recrystallized from water, yield $3.59 \mathrm{~g}(94 \%), \mathrm{mp}(\mathrm{dec}) .201{ }^{\circ} \mathrm{C}$. Anal. calc. $\%$ for $\mathrm{C}_{20} \mathrm{H}_{36} \mathrm{~N}_{4} \mathrm{O}_{4} \mathrm{Zr}(\mathrm{Mr}=887.75)$ : $\mathrm{C}$, $49.25 \%$; H, $7.44 \%$; O, $13.12 \%$; N, $11.49 \%$ Zr, $18.70 \%$. Found: C, $49.23 \%$; H, $7.11 \%$; O, $12.97 \%$; N, $11.25 \%$ $\mathrm{Zr}, 18.62 \%$.
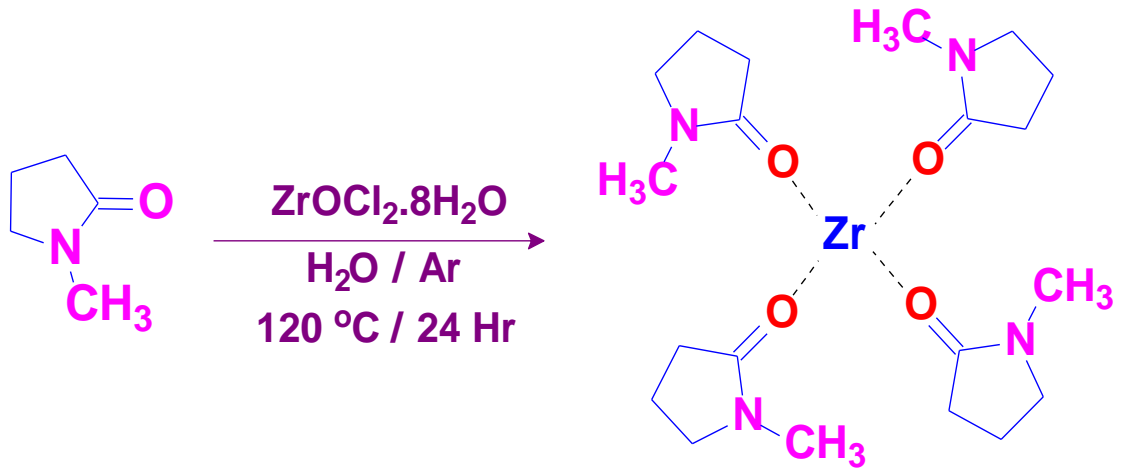

\section{T-NMP-Zr (Complex-II)}

Scheme 2. Synthesis of NMP functionalized $\mathrm{Zr}(\mathrm{IV})$ Complex

\section{Result and Discussions}

\subsection{Theoretical Chemistry}

A complex molecule can have various types of energy like bond and thermal energy. Molecular mechanics determine the steric energy of an element - the energy because of the geometry of a particle. The steric energy of the complexes is given in Table 1. Potential energy will be energy that is put away - or saved - in a substance.

This stored energy depends on the position, game plan, or condition of the item or substance. It is a potential that can possibly to do binding with other molecules. 
Table 1. Calculated minimized energies for T-R-Zr and T-NMP-Zr complexes

\begin{tabular}{|c|l|l|l|}
\hline Sl. No. & Calculated Values & T-R-Zr (Complex I) & T-NMP-Zr (Complex II) \\
\hline $\mathbf{1}$ & Stretch & 10.9241 & 4.2225 \\
\hline $\mathbf{2}$ & Bend & 89.2146 & 23.4924 \\
\hline $\mathbf{3}$ & Stretch-Bend & -5.1549 & 1.1141 \\
\hline $\mathbf{4}$ & Torsion & 125.6824 & 32.5554 \\
\hline $\mathbf{5}$ & Non-1.4 VDW & 6.3298 & -15.5376 \\
\hline $\mathbf{6}$ & 1.4 VDW & 42.6234 & 42.8458 \\
\hline $\mathbf{7}$ & Dipole & 1.6094 & 1.7231 \\
\hline $\mathbf{8}$ & Total Energy & $271.2288 \mathrm{Kcal} / \mathrm{mol}$ & $90.4157 \mathrm{Kcal} / \mathrm{mol}$ \\
\hline $\mathbf{9}$ & Potential Energy & $263.888 \pm 0.904$ & $94.992 \pm 0.184$ \\
\hline $\mathbf{1 0}$ & Steric Energy & $55: 243.613 \mathrm{kcal} / \mathrm{mole}$ & $708: 95.003 \mathrm{kcal} / \mathrm{mole}$ \\
\hline
\end{tabular}

\subsection{Electronic Absorption Spectroscopic Studies}

3.2.1. Absorption spectrum of ligand: The UV-Vis absorbance spectrum of the resacetophenone ligand in ethanol is presented in figure 1. In the UV-region, the ligand displays three distinct vibronic peaks for the intra ligand $\left(\pi \rightarrow \pi^{*}\right)$ charge transfer transitions characteristics of resacetophenone at 475,350 and $330 \mathrm{~nm}$. This ligand absorption is ascribed to the spin-allowed ligand charge transfer transitions (LCT).

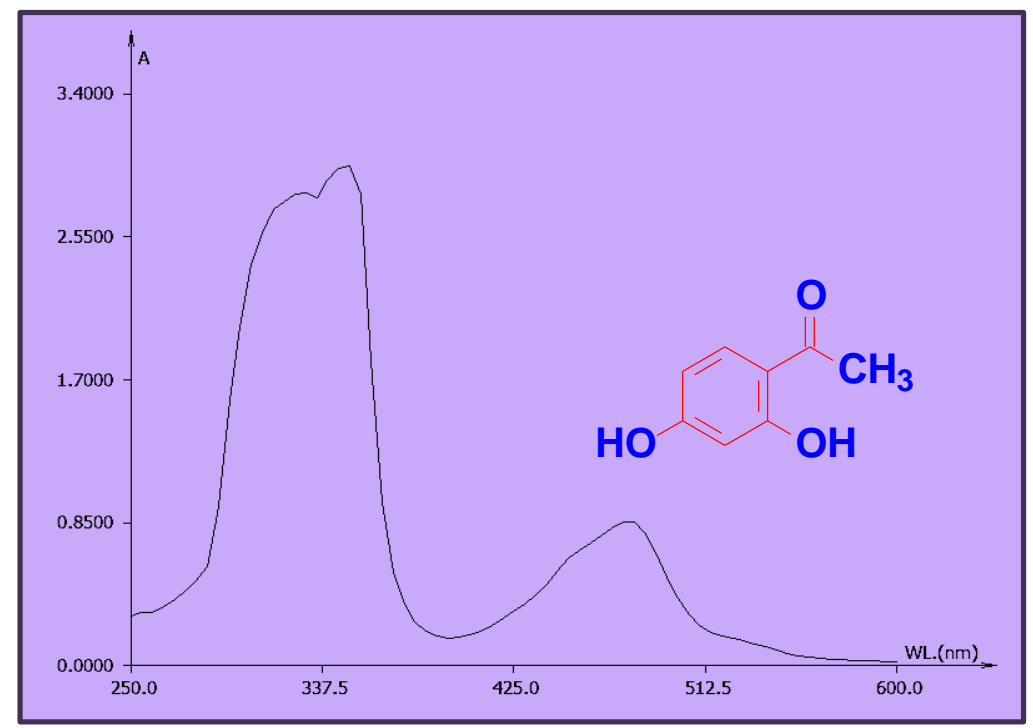

Fig.1. Uv- Vis Absorption spectrum of resacetophenone in ethanol

3.2.2. Absorption spectrum of $T-R-Z r$ complex (I): In the UV-region, the complex displays three distinct peaks for the intra ligand $\left(\pi \rightarrow \pi^{*}\right)$ charge transfer transitions characteristics of resacetophenone derivatives at 489,343 and $330 \mathrm{~nm}$. The complex shows broad absorption band at $489 \mathrm{~nm}$. This absorption is ascribed to the spin-allowed 
metal-to-ligand charge transfer transitions (MLCT). The UV-Vis absorbance spectrum of the tetraresacetophenone-Zr complex in water is presented in figure 2.

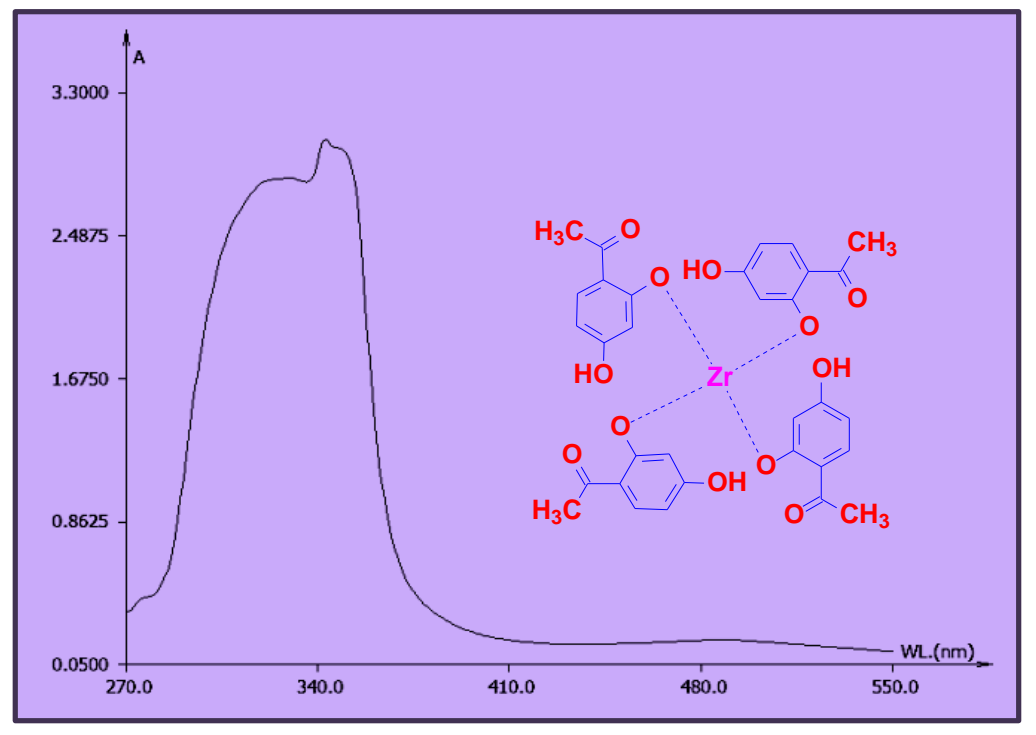

Fig.2. UV- Vis absorption spectrum of the complex (I) in water

3.2.3. Absorption spectrum of $T-R-Z r$ complex (I) with BSA: The UV-Vis absorbance spectrum of the complex (I) in water along with $4.5 \%$ of BSA is presented in figure 3. In the UV-region, the complex (I) displays two distinct broad peaks for the intra ligand $\left(\pi \rightarrow \pi^{*}\right)$ charge transfer transitions characteristics of resacetophenone derivatives at 342 and $328 \mathrm{~nm}$. In the presence of BSA protein the absorption values for the complex is shifted due to the polar interaction of metal complex with BSA. Due to this there is no separate metal center absorption was obtained. The blue shift in the absorption value from 343 to 342 and 330 to $328 \mathrm{~nm}$ confirms the binding of the complex with BSA protein.

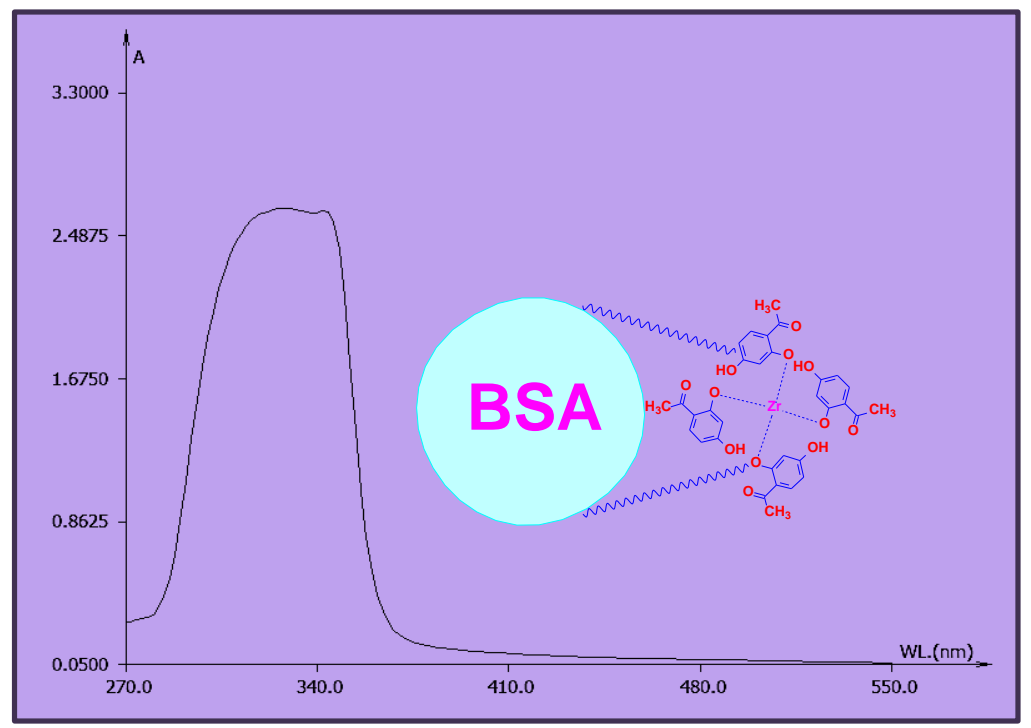

Fig.3. Uv-Vis absorption spectrum of complex (I) in BSA

3.2.4. Absorption spectrum of T-NMP-Zr complex (II): In the UV-region, the complex (II) displays a distinct intense peaks for the intra ligand $\left(\mathrm{n} \rightarrow \pi^{*}\right)$ charge transfer transitions characteristics of Pyrolidone unit at $299 \mathrm{~nm}$. 
This absorption is ascribed to the spin-allowed metal-to-ligand charge transfer transitions (MLCT). The UV-Vis absorbance spectrum of the complex (II) in water is presented in figure 4.

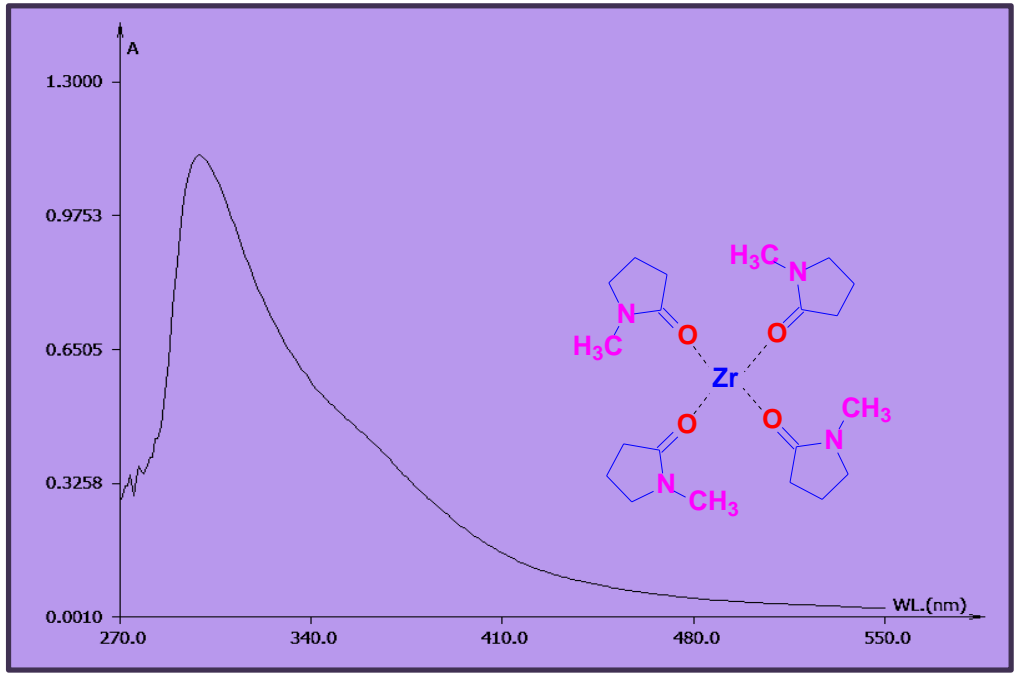

Fig.4. UV-VIS absorption spectrum of complex (II) in water

3.2.5. Absorption spectrum of T-NMP-Zr complex II with BSA: In the UV-region, the complex displays a separate sharp peaks for the intra ligand $\left(n \rightarrow \pi^{*}\right)$ charge transfer transitions characteristics of Pyrolidone unit at 294 $\mathrm{nm}$. In the presence of BSA protein the absorption values for the complex is shifted due to the polar interaction of metal complex with BSA. The blue shift in the absorption value from 299 to $294 \mathrm{~nm}$ confirms the binding of the complex with BSA protein. The UV-Vis absorbance spectrum of the complex (II) in water along with $4.5 \%$ of BSA is presented in figure 5 .

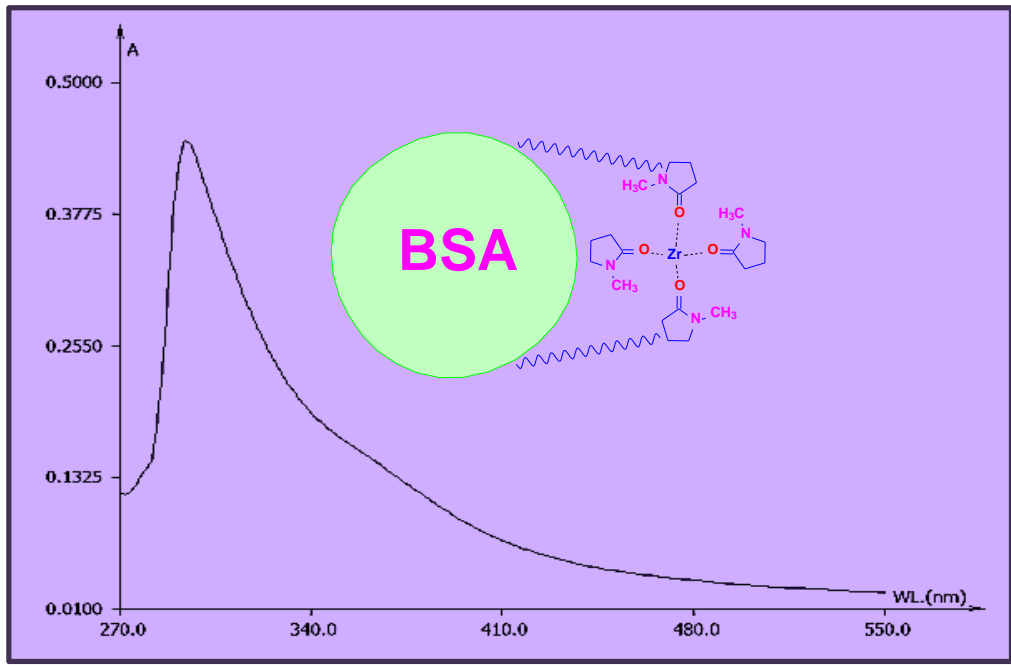

Fig.5. Uv-Vis absorption spectrum of the complex (II) with BSA

\subsection{Molecular docking study with COVID-19 virus}

\subsubsection{T-R-Zr Complex (I) docking with 6LU7}

It is a wide-reaching search among researcher to find a molecule, which can image the presence of Corona Virus-19 spike protein in human tissues in early stage itself. COVID-19 contains ALA, ARG, ASN, ASP, CYS, GLN, GLU, 
GLY, HIS, ILE, LEU, LYS, MET, PHE, PRO, SER, THR, TYR, and VAL types of amino acid links in their skeleton which makes the molecule high polar. Here we examine the binding efficiency of our complex I with the amino acid sequence in COVID-19 spike protein. Our highly polar complex I bind through $\pi$ - interaction with key amino acids like, ASP-248, 295, GLN-110, GLU-178, 288, GLY-179, 251, 283, ILE-249, LEU-250, LYS-5, MET-82, THR-292 and TRP-207 in COVID-19 spike protein with a coupling energy of $-7.0 \mathrm{kcal} \mathrm{mol}^{-1}$. The docking structure confirms that our complex easily bind with the main chain of the COVID-19 spike protein and gives information of the site where it presents. The conceivable hydrogen bonding cooperation between the edifices with the receptor has given in figure. 6 .
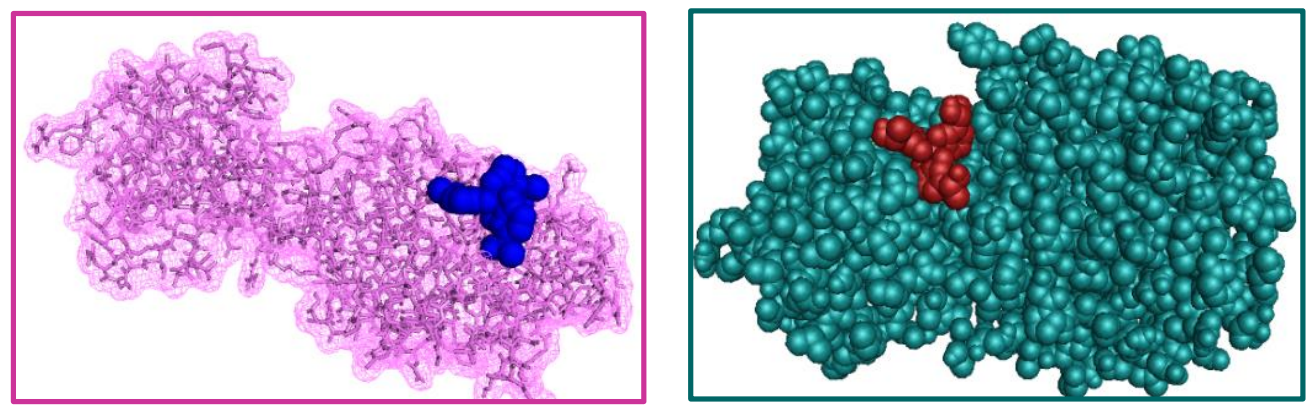

Fig.6. Molecular docking images of complex (I) with COVID-19 (PDB No.: 6LU7)

\subsubsection{T.NMP-Zr Complex (II) docking with 6LU7}

Similarly we examine the binding efficiency of our complex II with the amino acid sequence in COVID-19 spike protein. Since the complex is high polar and flexible it binds strongly through $\pi$-interaction with key amino acids like, ASN-151, ASP-245, GLN-110, GLY-290, ILE-106, LYS-102, PHE-294, and THR-111, 292 in COVID-19 spike protein with a coupling energy of $-4.9 \mathrm{kcal} \mathrm{mol}^{-1}$. The docking structure confirms that our complex easily buried in the main chain protease of the COVID-19 spike protein and gives information of the site where it presents. The conceivable hydrogen bonding cooperation between the edifices with the receptor has given in figure 7 .
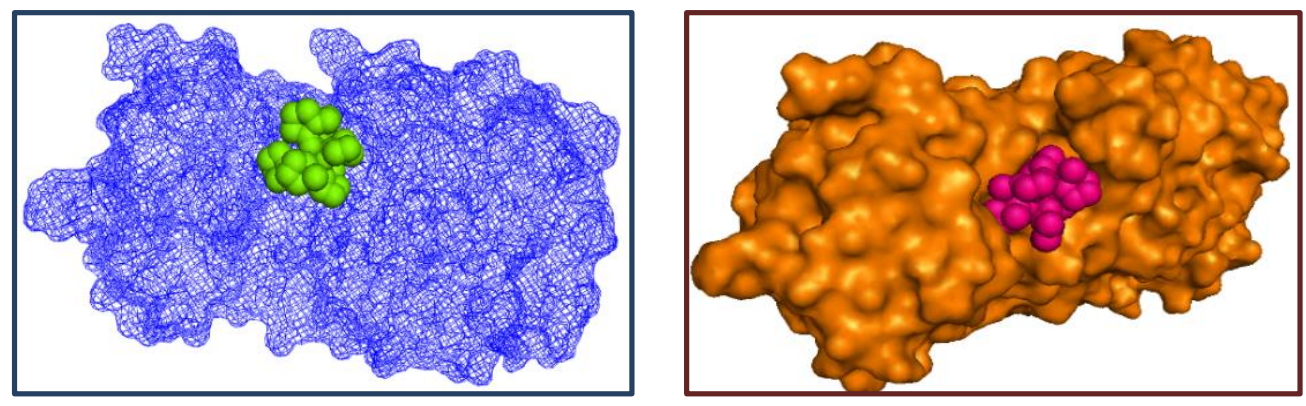

Fig.7. Molecular docking images of the complex (II) with COVID-19 (PDB No.: 6LU7)

\subsubsection{Discussion on Molecular Docking Studies}

The study of evolving epidemiology and spread of COVID-19 pandemic is very vital to accumulate 'timely facts to information intervention policy. We recognize that the coronavirus has massive +ve strand RNA uses for replication referred to as 'S' Spike proteins. This replication will begin when it binds over the ACE2 receptor in the human lungs, kidneys, GI track, and Brain. Then it will enter the cell cytoplasm and it replicates with the help of an 
RNA-dependent RNA polymerase (RdRp). So for inhibiting the replication of the virus it is must target the amino acid which is supporting the virus to replicate or grant strength both by conversion or by way of cleavage. In earlier research, it is observed that the key amino acids like ARG, GLY, and SER are distinctly worried in virus genome replication. Any drug or chemical agent which has the capability to anchor these amino acids on the spike protein will act as the better virus replication inhibiter. Our complexes exhibit higher molecular binding in the area of spike proteins and rather anchor with the amino acid-like GLY-179, 251, 283, 290, respectively. It is all due to the fact of the high polar nature of the ligands. The finding led us a way to increase a new and efficient drug towards the covid-19 outbreak. The antiviral research will give extra promising consequences than the currently using drugs.

\section{Conclusion}

The simple and excessive yield laboratory based synthetic technique has been tailored for the synthesis of ligand and $\mathrm{Zr}(\mathrm{IV})$ metal complexes, respectively. Our complexes exhibit very high-quality potential, thermal, and steric energy. The UV-visible absorption spectrometry was once applied to look into the electronic absorption conduct of the metallic complexes insolvent and the interplay with BSA. The exchange in absorption values both blue and redshift indicates that the metal strongly binds to BSA by and large by using hydrogen bonds and van der Waals interactions. All the two heterocyclic ligand-based metal complexes confirmed the satisfactory anchoring over the main protease in SARS-Cov-2 with binding energies of -7.0 and $-4.9 \mathrm{kcal} / \mathrm{mol}$, respectively. This makes them possible lead compounds for improvement into candidates in antiviral drug to the SARS-COV-2. We, therefore, extended these lead compounds to tried for COVID-19 virus replication inhibition management.

\section{Declarations}

\section{Source of Funding}

This research did not receive any specific grant from funding agencies in the public, commercial, or not-for-profit sectors.

\section{Competing Interests Statement}

The authors declare no competing financial, professional and personal interests.

\section{Ethical Approval}

Ethical approval for this research was given based on institutional guidelines.

\section{Consent to participate}

The consent to participate in this research was sought for and approved by the subjects to be used.

\section{Consent for publication}

We declare that we consented for the publication of this research work.

\section{Availability of data and material}

Authors are willing to share data and material according to the relevant needs. 


\section{References}

[1] Freiria, A., Bastida, R., Valencia, L., Macias, A. and Lodeiro, C. Inorganica Chi. Acta, 2006, 359, 2383- 2394.

[2] Mobinikhaledi, N. Forughifar, and M. Kalhor, Turkish Journal of Chemistry, 2010, 34, 367-373.

[3] A. K. Singh, O. P. Pandey, and S. K. Sengupta, Spectrochimica Acta—Part A: Molecular and Biomolecular Spectroscopy. 2012, 85, 1-6.

[4] G. B. Bagihalli, P. G. Avaji, S. A. Patil, and P. S. Badami, European Journal of Medicinal Chemistry, 2008, 43, 2639-2649.

[5] K. S. Bhatki, Rev. Anal. Chem., 2011, 8, 211.

[6] V. K. Reddy, S. M. Reddy, P. R. Reddy and T. S. Reddy, Ind. J. Chem., 2000, 39A, 557.

[7] S. Baluja, A. Solanki and N. Kachhadia, J. Iranian Chem. Soc., 2006, 3, 312.

[8] M. S. S. Babu, K. H. Reddy and P. G. Krishna, Polyhedron., 2007, 26, 572.

[9] Pharmasolve Drug Solubilizer, Pharma Guide, Int. Specialty Products, a division of Ashland Inc.: pp.9, 2012.

[10] Bengt Åkesson, Department of Occupational \& Environmental Health, University Hospital, Lund, Sweden. World Health Organization Geneva, 2001.

[11] Rothan, H.A.; Byrareddy, S.N. The epidemiology and pathogenesis of coronavirus disease (COVID-19) outbreak. J Autoimmun 2020, 109, 102433.

[12] Rothan, H.A.; Acharya, A.; Reid, S.P.; Kumar, M.; Byrareddy, S.N. Molecular Aspects of COVID-19 Differential Pathogenesis. Pathogens 2020, 9, 538.

[13] Espinosa, P.S.; Rizvi, Z.; Sharma, P.; Filatov, A. Neurological Complications of Coronavirus Disease (COVID-19): Encephalopathy, MRI Brain and Cerebrospinal Fluid Findings: Case 2. Cureus 2020, 12, 7930.

[14] Filatov, A.; Sharma, P.; Hindi, F.; Espinosa, P.S. Neurological Complications of Coronavirus Disease (COVID-19): Encephalopathy. Cureus 2020, 12, 7352.

[15] Heneka, M.T.; Golenbock, D.; Latz, E.; Morgan, D.; Brown, R. Immediate and long-term consequences of COVID-19 infections for the development of neurological disease. Alzheimer's research \& therapy 2020, 12, 69.

[16] Mahammedi, A.; Saba, L.; Vagal, A.; Leali, M.; Rossi, A.; Gaskill, M.; Sengupta, S.; Zhang, B.; Carriero, A.; Bachir, S., et al. Imaging in Neurological Disease of Hospitalized COVID-19 Patients: An Italian Multicenter Retrospective Observational Study. Radiology 2020.

[17] Parry, A.H.; Wani, A.H.; Yaseen, M. Neurological Dysfunction in Coronavirus Disease-19 (COVID-19). Academic radiology 2020, 27, 1329-1330.

[18] Baig, A.M.; Sanders, E.C. Potential neuroinvasive pathways of SARS-CoV-2: Deciphering the spectrum of neurological deficit seen in coronavirus disease-2019 (COVID-19). Journal of medical virology 2020. 
[19] Adamczyk-Sowa, M.; Niedziela, N.; Kubicka-Baczyk, K.; Wierzbicki, K.; Jaroszewicz, J.; Sowa, P. Neurological symptoms as a clinical manifestation of COVID-19: implications for internists. Polish archives of internal medicine 2020.

[20] Wang, H.Y.; Li, X.L.; Yan, Z.R.; Sun, X.P.; Han, J.; Zhang, B.W. Potential neurological symptoms of COVID-19. Therapeutic advances in neurological disorders 2020, 13.

[21] Pushparaj L T., Alexander, V. 'Trinuclear Gd(III) Metal Complex with Amide Core Display Remarkable Enhancement in Relaxivity’. App. Mag. Res., 2017, 48, 813-825.

[22] Pushparaj L T., Uma, D M. 'Developing Novel Coumarone-Phenyl Amide Functionalized [Gd(III)-Pt(IV)] Complex as High T1, T2 Relaxive M-MRI Contrast Agent for Cancer Diagnosis'. Irish Interdisciplinary Journal of Science \& Research, 2021, 5, 51-63.

[23] Pushparaj L T., Francy I R E., M. Uma, D M. 'HSA and CA-125 Binding Study of [Pr-(DO3-Ch-Ph-AmGd(III))2Pt(IV)] Complex as M-MRI Contrast Agent for Ovarian Cancer Treatment'. JIDPTS, 2021, 4, 1-8.

[24] Pushparaj L T., Francy I R E., Sathya, S. “Therapeutic Properties of Gd(III)-Ir(III) Complex for Non-invasive Detection of Ovarian Cancer Through M-MR Imaging'. Irish Interdisciplinary Journal of Science \& Research, 2021, 5, 23-33.

[25] Pushparaj L T., Sathya, S. 'Novel Designing of Ir(III)(Tris-Coumarin) Cored Gd(III) Complex as Targeted MRI CAs for Ovarian Cancer Treatment', Irish Interdisciplinary Journal of Science \& Research, 2021, 5, 7-17.

[26] Trott, O., Olson, A. J. AutoDock Vina: improving the speed and accuracy of docking with a new scoring function, efficient optimization and multithreading, J. Comp. Chem., 2010, 31, 455-461.

[27] Ahluwalia, V. K; Aggarwal, R., Comprehensive Practice Organic Chemistry: Preparation and Quantitative Analysis; Edision 1, Universities Press (India) Limited, 2000, pp1-312. 